\title{
A Generalized Two Axes Modeling, Order Reduction and Numerical Analysis of Squirrel Cage Induction Machine for Stability Studies
}

\author{
Sudhir Kumar and P. K. Ghosh \\ Faculty of Engineering and Technology \\ Mody Institute of Technology and Science \\ Lakshmangarh, District Sikar \\ Rajasthan 332311, India \\ skumar_icfai@yahoo.co.in,pkghosh_ece@yahoo.co.in
}

\author{
S. Mukherjee \\ Department of Electrical Engineering \\ Indian Institute of Technology \\ Roorkee, Uttrakhand, India \\ mukherjee.shaktidev@gmail.com
}

\begin{abstract}
A substantial amount of power system load is made of large number of three phase induction machine. The transient phenomena of these machines play an important role in the behavior of the overall system. Thus, modeling of induction machine is an integral part of some power system transient studies. The analysis takes a detailed form only when its modeling becomes perfect to a greater accuracy. When the stator eddy current path is taken into account, the uniform air-gap theory in phase model analysis becomes inefficient to take care of the transients. This drawback necessitates the introduction of analysis of the machine in $d-q$ axis frame. A widely accepted induction machine model for stability studies is the fifth-order model which considers the electrical transients in both rotor and stator windings and the mechanical transients. In practice, some flux-transient can be ignored due to the quasi-stationary nature of the variables concerned. This philosophy leads to the formation of reduced order model. Model Order Reduction (MOR) encompasses a set of techniques whose goal is to generate reduced order models with lower complexity while ensuring that the $I / O$ response and other characteristics of the original model (such as passivity) are maintained. This paper takes the above matter as a main point of research. The authors use the philosophy of the speed-build up of induction machine to find the speed versus time profile for various load conditions and supply voltage disturbances using numerical methods due to RungeKutta, Trapezoidal and Euler's in Matlab platform. The established fact of lesser computation time in reduced order model has been verified and improvement in accuracy is observed.
\end{abstract}

Keywords- Induction machine, Model order reduction, Stability, Transient analysis.

\section{INTRODUCTION}

The mathematical description of many physical systems when obtained using theoretical considerations often results in large-order models. To be more precise, in the time domain or state space representation, the modeling procedure leads to a high order state space model and a higher order transfer function model in frequency domain representation. It is often desirable for analysis, simulation and system design to represent such models by equivalent lower order state variable or transfer function models which reflect the dominant characteristics of the system under consideration. Model order reduction is important and common theme within the simulation, control and optimization of complex physical processes. Some of the reason for using reduced order models of higher order system could be (i) to have a better understanding of the system (ii) to reduce computational complexity (iii) to reduce hardware complexity and (iv) to make feasible controller design. The Model order reduction techniques for both type of reduction have been proposed by several researchers. A large number of methods are available in the literature for order reduction of linear continues systems in time domain as well as in frequency domain [1-7]. The extension of single input single output (SISO) methods to reduce multi input multi output (MIMO) systems has been also carried out in [8-11]. Numerous methods of order reduction are also available in the literature [12-17], which are based on the minimization of the integral square error criterion. Some of methods are based on stability criterion. Each of these methods has both advantages and disadvantages when tried on a particular system. In spite of several methods available, no approach always gives the best results for all the systems.

In this paper, two axes modeling (d-q model) using park's transformation theory in state space representation has been developed and reduced order model has also been derived and simulation results are obtained using various numerical methods such as Runge-Kutta, Trapezoidal and Euler method under no load and load conditions and supply voltage disturbances.

Further, it is well known fact that the three phase Induction machines are the work-force in the generator-mode and motormode applications in the power systems. As induction motors are becoming day by day a main component of A.C drive systems, a detailed study of the different aspects of its modeling draws the attention of the researchers [18-31]. The important approach of modeling of induction machine is the Park's transformation theory, which converts the machine from phase model to axis model. Two separate coils are assumed to lie on each axis, both for stator and rotor of the induction machine. The voltage balance equations for each coil are formulated and then the torque-balance equation of the machine is established. As transformer emf is a component of voltage balance equation, the machines equation involves the 
time rate of changes of flux linkage ' $(\mathrm{P \Psi})$ ', where $\mathrm{p}$ stands for the time derivative and ' $\Psi$ ' is flux-linkage associated with each coil. The number of $\mathrm{P}$-terms in complete model indicates the order of the model.

This work investigates the different aspects of reduced order modeling of the three-phase induction motor as a power system component. In power system simulation, especially in the transient stability studies, it is desirable to represent induction motor loads with a reduced-order model in order to decrease computational efforts and time. The order reduction is achieved by setting the derivative of stator flux linkage to zero in the stator differential equation in which all equations are referred to the synchronously revolving reference frame. This method of reducing the order of the induction machine is designated as the theory of neglecting stator flux transients.

\section{Basic Assumption And Model Of Single Cage THREE PHASE INDUCTION MACHINE}

The theory of neglecting stator flux transients applied to induction motor, the axis equation modeled in synchronously rotating reference frame requires two assumptions, and these are:

(i) Terminal voltage cannot continually change in magnitude at a high rate for any length of time and it must remain at synchronous frequency

(ii) Oscillating torque component caused by stator flux linkage transients can be safely ignored.

The methods of deriving reduced order equations are described below.

For reducing the order of the model of single cage type of Induction machine, stator flux transients have been neglected. The simplest method of deriving linearized reduced order models of induction machine is the identification of the Eigen- values/poles in the frequency domain and to neglect the faster transient. Therefore, for required process of model order reduction, the time domain equations are to be transformed into Laplace domain. Avoiding the process, one can also reduced the model order, if he assumes rotor resistance of larger value and this involves higher starting torque. The rotor copper loss will increase and efficiency will be poor. Thus the rotor flux transient cannot be neglected.

The transient performance of electrical machines has received increasing attention in recent years primarily due to the application of digital computers to large and complicated models of electromechanical systems [18-29]. Computer simulation of induction machine is performed to determine the machine behavior under various abnormal operating conditions such as start up and sudden change in supplies voltage and load torque, etc.

The detailed induction machine model is non-linear fifth order model, which is referred to as the "full order model". This model takes into account the electrical transients of both the stator and rotor windings, requires a relatively large amount of computational time. Consequently, the third-order model is achieved through neglecting the electrical transients of stator winding, is used to predict the transient behavior of induction motors.

\section{FORMULATION OF FULL- ORDER MODEL OF SINGLE CAGE INDUCTION MACHINE}

The reduced order model is derived from the full order model of induction machine. The mathematical model is expressed in synchronously rotating $\mathrm{d}-\mathrm{q}$ references frame using per unit system. The machine flux linkages are selected as state variables and the power invariant transformation is used to convert the phase variable to their equivalent $d-q$ variable.

\section{A. Full- Order Model (5th-Order Model)}

The induction machine equations are expressed in synchronously rotating frame of reference:

$$
\begin{aligned}
& \mathrm{P} \psi_{\mathrm{sd}}=-\mathrm{a}_{1} \psi_{\mathrm{sd}}+\psi_{\mathrm{sq}}+\mathrm{a}_{2} \psi_{\mathrm{rd}}+\mathrm{V}_{\mathrm{sd}} \\
& \mathrm{P} \psi_{\mathrm{sq}}=-\psi_{\mathrm{sd}}-\mathrm{a}_{1} \psi_{\mathrm{sq}}+\mathrm{a}_{2} \psi_{\mathrm{rq}}+\mathrm{V}_{\mathrm{sq}} \\
& \mathrm{P} \psi_{\mathrm{rd}}=\mathrm{a}_{3} \psi_{\mathrm{sq}}+\mathrm{a}_{4} \psi_{\mathrm{rq}}-\left(1-\mathrm{w}_{\mathrm{r}}\right) \psi_{\mathrm{rd}} \\
& \mathrm{P} \psi_{\mathrm{rq}}=\mathrm{a}_{3} \psi_{\mathrm{sd}}+\left(1-\mathrm{w}_{\mathrm{r}}\right) \psi_{\mathrm{rq}}-\mathrm{a}_{4} \psi_{\mathrm{rd}} \\
& \mathrm{P}_{\mathrm{r}}=\left(\mathrm{L}_{\mathrm{m}} / 2 \mathrm{HL} \mathrm{L}_{\mathrm{sr}}\right)\left[\left(\psi_{\mathrm{sq}} \psi_{\mathrm{rd}}-\psi_{\mathrm{sd}} \psi_{\mathrm{rq}}\right)-\left(\mathrm{L}_{\mathrm{sr}} \mathrm{T}_{\mathrm{L}} / \mathrm{L}_{\mathrm{m}}\right)\right]
\end{aligned}
$$

where,

$$
\begin{aligned}
& \mathrm{a}_{1}=\mathrm{R}_{\mathrm{s}} \mathrm{L}_{\mathrm{rr}} / \mathrm{L}_{\mathrm{sr}}, \mathrm{a}_{2}=\mathrm{R}_{\mathrm{s}} \mathrm{L}_{\mathrm{m}} / \mathrm{L}_{\mathrm{sr}}, \mathrm{a}_{3}=\mathrm{R}_{\mathrm{r}} \mathrm{L}_{\mathrm{m}} / \mathrm{L}_{\mathrm{sr}}, \\
& \mathrm{a}_{4}=\mathrm{R}_{\mathrm{r}} \mathrm{L}_{\mathrm{ss}} / \mathrm{L}_{\mathrm{sr}}
\end{aligned}
$$

The quantities $\psi_{\text {sd }}$ and $\psi_{\text {sq }}$ are the flux linkage of the stator winding along direct and quadrature axes respectively. $\psi_{\mathrm{rd}}$ and $\psi_{\mathrm{rq}}$ refer to those for rotor winding. $\mathrm{R}_{\mathrm{r}}$ and $\mathrm{R}_{\mathrm{s}}$ are the winding resistance of rotor and stator respectively. $\mathrm{L}_{\mathrm{ss}}$ and $\mathrm{L}_{\mathrm{rr}}$ represent the self-inductance of stator and rotor winding respectively, while $\mathrm{L}_{\mathrm{sr}}$ denotes the mutual inductance between them. The quantities $L_{s}$ and $L_{r}$ are the apparent three phase rotor and stator self-inductance respectively and $\mathrm{L}_{m}$ is the magnetizing inductance in the winding. The quantities $\mathrm{V}_{\mathrm{sd}}$ and $\mathrm{V}_{\mathrm{sq}}$ refer to the stator terminal voltage along $\mathrm{d}$ and $\mathrm{q}$ axes respectively. $\mathrm{H}$ is the inertia constant in second. We have the relations

$$
\begin{aligned}
& \mathrm{L}_{\mathrm{ss}}=\mathrm{L}_{\mathrm{s}}+\mathrm{L}_{\mathrm{m}} \\
& \mathrm{L}_{\mathrm{rr}}=\mathrm{L}_{\mathrm{r}}+\mathrm{L}_{\mathrm{m}} \\
& \mathrm{L}_{\mathrm{sr}}=\mathrm{L}_{\mathrm{rr}} \mathrm{L}_{\mathrm{ss}}-\mathrm{L}_{\mathrm{m}}{ }^{2}
\end{aligned}
$$

The phase voltages $\mathrm{V}_{\mathrm{a}}, \mathrm{V}_{\mathrm{b}}$ and $\mathrm{V}_{\mathrm{c}}$ may be expressed in matrix form as

$$
\left[\begin{array}{c}
V_{a} \\
V_{b} \\
V_{c}
\end{array}\right]=V_{m}\left[\begin{array}{c}
\sin \theta \\
\sin (\theta-2 \pi / 3) \\
\sin [\theta+2 \pi / 3]
\end{array}\right]
$$

The $\mathrm{d}-\mathrm{q}$ voltage are related to the phase voltage by the expression 


$$
\begin{aligned}
& {\left[\begin{array}{c}
V_{\text {sd }} \\
\mathrm{V}_{\mathrm{sq}}
\end{array}\right]=} \\
& \sqrt{\frac{2}{3}}\left[\begin{array}{ccc}
\sin \theta & \sin (\theta-2 \pi / 3) & \sin (\theta+2 \pi / 3) \\
\cos \theta & \cos (\theta-2 \pi / 3) & \cos (\theta+2 \pi / 3)
\end{array}\right]\left[\begin{array}{l}
V_{a} \\
V_{b} \\
V_{c}
\end{array}\right]
\end{aligned}
$$

In equation (10) and (11), $\theta=\mathrm{wt}+\alpha$ is the phase angle, and $\alpha$ is the switching time.

The Stator d-q currents expressed in term of flux linkage can be written as

$$
\left[\begin{array}{l}
i_{s d} \\
i_{s q}
\end{array}\right]=\left[\begin{array}{l}
\left(L_{r r} \psi_{s d}-L_{m} \psi_{r d}\right) / L_{s r} \\
\left(L_{r r} \psi_{s q}-L_{m} \psi_{r q}\right) / L_{s r}
\end{array}\right]
$$

Representing by $\mathrm{p}$ and $\mathrm{q}$ the active and reactive powers, we may have the matrix equation:

$$
\left[\begin{array}{l}
P \\
\mathrm{Q}
\end{array}\right]=\left[\begin{array}{cc}
V_{s d} & V_{s q} \\
V_{s q} & -V_{s d}
\end{array}\right]\left[\begin{array}{l}
i_{s d} \\
i_{s q}
\end{array}\right]
$$

Simulation results are obtained using various numerical methods such as Runge-Kutta, Trapezoidal and Euler method under no load and load conditions and supply voltage disturbances. The flowchart for simulation algorithm is given in figure 1.

\section{FORMULATION OF REDUCED-ORDER MODEL OF SINGLE CAGE INDUCTION MOTOR}

Reduced order model applied to normal three-phase induction Machine of single cage design allows to neglect the stator flux Transient. This assumption makes the $\mathrm{d} / \mathrm{dt}=\mathrm{P}$ terms reduced in comparison to full order model hence the resulting matrixes of flux-linkage equation will be simpler and computational time will be less.

\section{Neglecting Stator Transient}

The fifth-order model is reduced to the third order model by setting the time rate of change of the stator flux linkage to zero. Solving these flux linkages after setting their derivatives to zero in (1) and (2) yields

$$
\begin{aligned}
& {\left[\begin{array}{l}
\psi_{\text {sd }} \\
\psi_{\mathrm{sq}}
\end{array}\right]=} \\
& \frac{1}{a_{1}^{2}+1}\left\{\left[\begin{array}{cc}
a_{1} a_{2} & a_{2} \\
-a_{2} & a_{1} a_{2}
\end{array}\right]\left[\begin{array}{l}
\psi_{r d} \\
\psi_{r q}
\end{array}\right]+\left[\begin{array}{cc}
a_{1} & 1 \\
-1 & a_{1}
\end{array}\right]\left[\begin{array}{l}
V_{s d} \\
V_{s q}
\end{array}\right]\right\}
\end{aligned}
$$

Substituting above in (3)-(5) results in the third order model

$$
\begin{gathered}
\frac{d \psi_{r d}}{d t}=\left(b_{1}-\varpi_{r}\right) \psi_{r q}+b_{2} \psi_{r d}+b_{3} V_{s q}+b_{4} V_{s d} \\
\frac{d \psi_{r q}}{d t}=b_{2}-\psi_{r q}-\left(b_{1}-\varpi_{r}\right) \psi_{r d}-b_{4} V_{s q}-b_{3} V_{s d} \\
\frac{d \psi_{r}}{d t}=\frac{L_{m}}{2 H L_{s r}\left(a_{1}^{2}+1\right)} \\
\left\{\begin{array}{l}
-a_{2}\left(\psi_{d r}^{2}+\psi_{q r}^{2}\right)-\frac{L_{s r}^{2}\left(a_{1}^{2}+1\right)}{L_{m}} T_{1}\left(a_{1} v_{s d}+v_{s q}\right) \psi_{q r} \\
+\left(a_{1} v_{s q}+v_{s d}\right) \psi_{d r}
\end{array}\right\}
\end{gathered}
$$

where

$$
\begin{gathered}
b_{1}=1+\frac{a_{2} a_{3}}{a_{1}^{2}+1}, b_{2}=a_{4}+\frac{a_{1} a_{2} a_{3}}{a_{1}^{2}+1} \\
b_{3}=\frac{a_{3}}{a_{1}^{2}+1}, \quad b_{4}=a_{4}+\frac{a_{1} a_{3}}{a_{1}^{2}+1} .
\end{gathered}
$$

\section{RESULTS AND DisCUSSIONS}

The simulation results and performance characteristics of full order model and reduced order of single cage induction machine for stator current, stator flux linkage, rotor speed etc. have been obtained as shown in figures $2(\mathrm{a}-\mathrm{c})$ and $3(\mathrm{a}-\mathrm{c})$ under no load and load torque disturbances and supply voltages changes. The machine parameters for the single cage induction machine under analysis are given in table I.

Reduced order model characteristics have been compared with their full order model. The characteristics obtained for full order model and reduced order model are almost equal. The computational time obtained for full order model and reduced order model using three numerical methods are also compared in table II. The algorithm presented in this paper introduces a considerable advantage in computational speed as indicted by comparative results given in the table II.

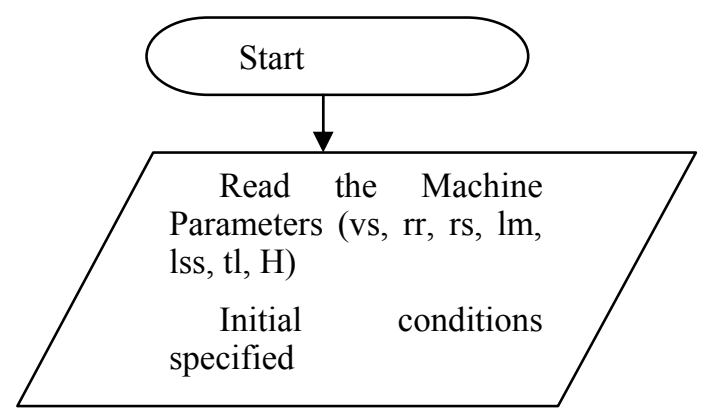

$65 \mid \mathrm{P}$ a g e 
$\downarrow$

Compute the base value and transfer machine parameters in P.U system

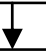

Store the output specifications

Calculate the phase voltages and stator terminal voltages along $\mathrm{d}-\mathrm{q}$ axis using subroutine program

Calculate the stator and rotor flux linkages of $\mathrm{d}$-q axis from equation (1)(4)using three methods(i) Runge-kutta fourth order method(ii)Trapezoidal method(iii)Euler method

(Te)

Calculate the electromagnetic Torque

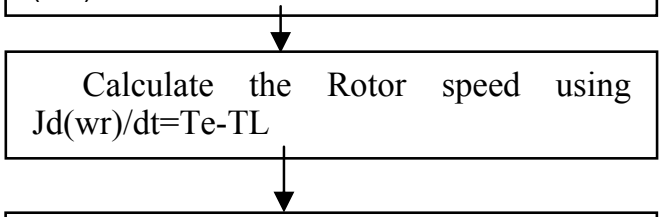

Print the result of speed, flux linkage, current of induction machine at no load \& load and supply voltages disturbances

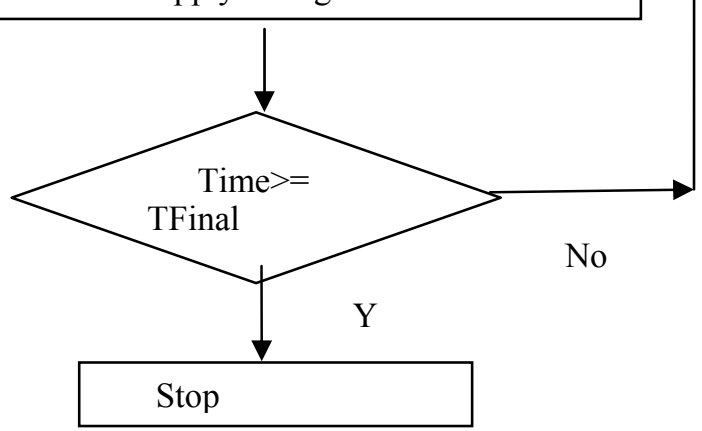

Figure 1: Flow chart of simulation algorithm

TABLE I. SPECIFICATION AND MACHINE PARAMETERS OF SINGLE CAGE INDUCTION MACHINE

\begin{tabular}{|l|c|}
\hline 2 HP, 1200 RPM, 6 Pole, 60 Hz, THREE PHASE MACHINE \\
\hline Machine parameters & P.U Value \\
\hline Supply Voltage & 200 \\
\hline Stator Resistance $\left(\mathrm{R}_{\mathrm{s}}\right)$ & 0.1742 \\
\hline Rotor Resistance $\left(\mathrm{R}_{\mathrm{r}}\right)$ & 0.0637 \\
\hline Self Inductance of stator winding $\left(\mathrm{L}_{\mathrm{ss}}\right)$ & 1.754 \\
\hline
\end{tabular}

\begin{tabular}{|c|c|}
\hline $\begin{array}{l}\text { Mutual Inductance between Stator \& Rotor } \\
\left(\mathrm{L}_{\mathrm{sr}}\right)\end{array}$ & 2.475 \\
\hline Magnetizing Inductance $\left(\mathrm{L}_{\mathrm{m}}\right)$ & 1.65 \\
\hline Inertia Constant $(\mathrm{H})$ & $0.0331 \mathrm{sec}$ \\
\hline $\begin{array}{l}\text { Mutual Inductance between stator and } \\
\text { rotor }\left(L_{\mathrm{sr}}\right)\end{array}$ & 2.475 \\
\hline
\end{tabular}

TABLE II. COMPARISON OF COMPUTATIONAL TIME OBTAINED FOR FULL ORDER AND REDUCED ORDER MODELS IN THREE NUMERICAL METHODS USING MATLAB

\begin{tabular}{|l|l|}
\hline \multicolumn{2}{|l|}{ Runge-Kutta (RK4) Solver } \\
\hline Model & Computation Time(ms) \\
\hline Full order model & 491 \\
\hline Reduced order model & 282 \\
\hline Trapezoidal Solver & Computation Time(ms) \\
\hline Model & 545 \\
\hline Full order Model & 312 \\
\hline Reduced order model & \\
\hline Euler Solver & Computation Time(ms) \\
\hline Model & 402 \\
\hline Full order Model & 235 \\
\hline Reduced order model &
\end{tabular}

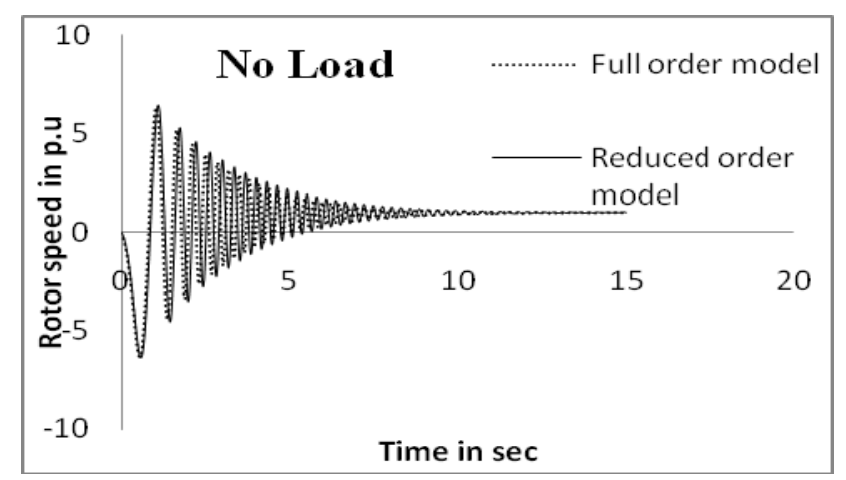

Figure: 2 (a)

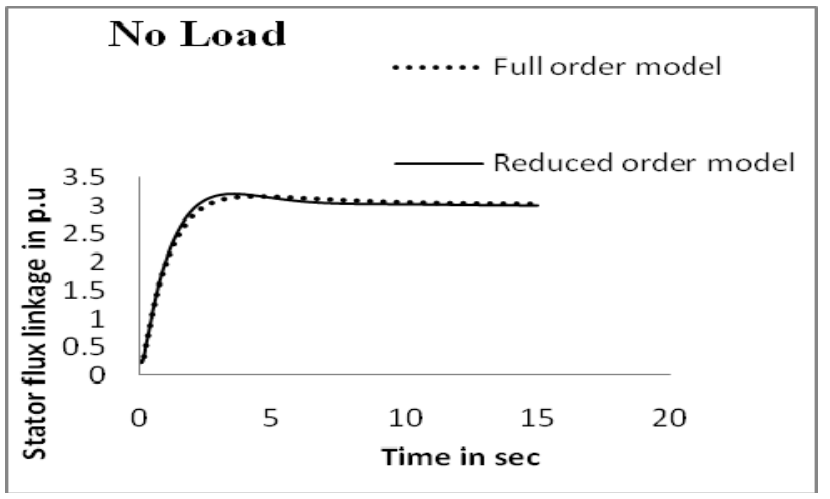

Figure: 2 (b)

$66 \mid \mathrm{P}$ a g e 


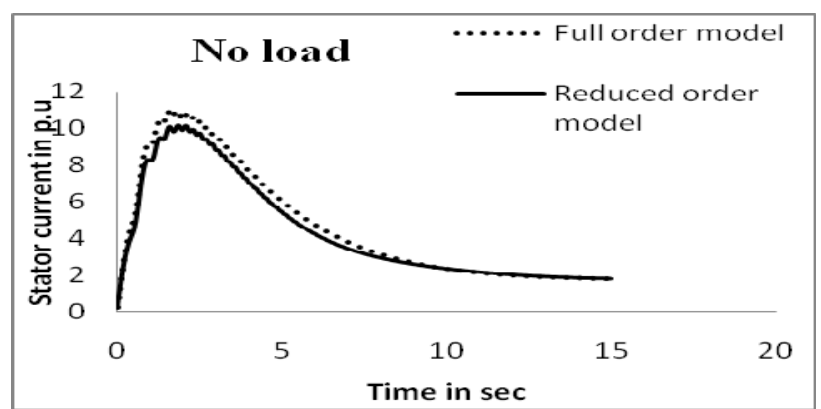

Figure: 2(c)

Fig2 (a-c): Response of Full order Model \& Reduced order model under no load condition and at rated supply voltage

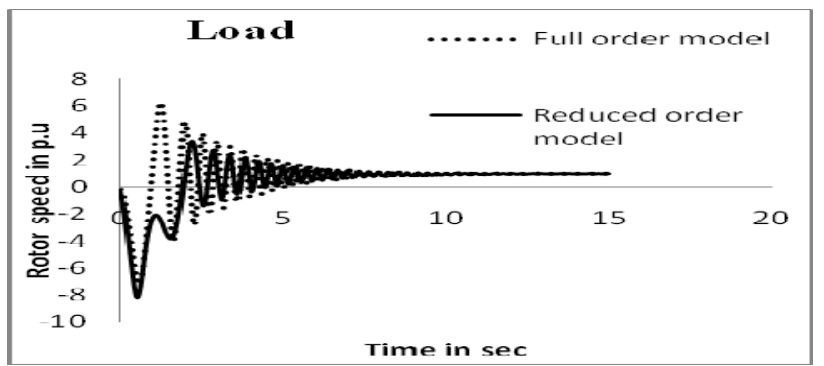

Figure: $3(a)$

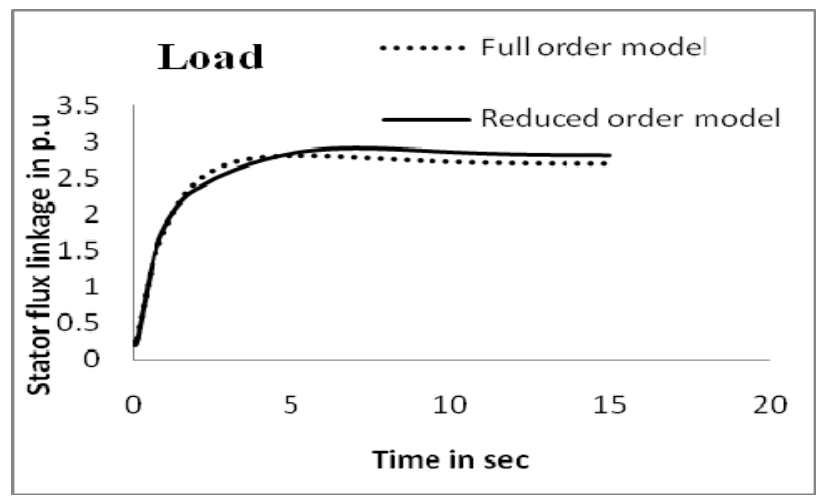

Figure: 3 (b)

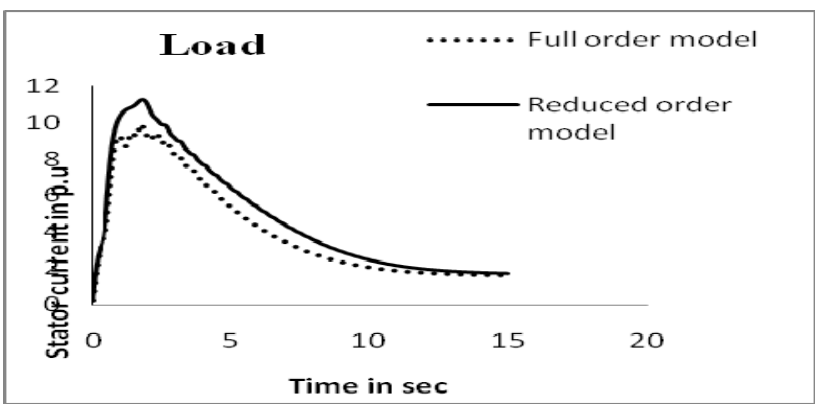

Figure: 3(c)

Figure 3(a-c): Response of Full Order Model \& Reduced order

Model under load condition and supply voltage change (10\%)

\section{CONCLUSIONS}

The reduced order model of single cage induction machine was validated by digital simulation and compared with the response of full order model using three numerical methods such as Runge-Kutta method, Trapezoidal method and Euler's method. The reduced order model is applied to a $2 \mathrm{HP}, 1200$ rpm, 6 pole, $60 \mathrm{~Hz}$ single cage induction machine and its performance characteristics is compared with the full order model. The performance characteristic of reduced order model is approximately same as full order model of single cage induction machine. The simulation time taken for full order and reduced order models are calculated using three numerical methods. The results show the saving of considerable amount of time in reduced order model as compared to full order model.

The numerical techniques, namely, Runge-Kutta method Trapezoidal method and Euler's method for solving the non-linear differential equation using MATLab are used to integrate the differential equation and integration size is taken to be 0.002 second. The quantities selected for simulation are stator current, stator flux-linkages, rotor speed under no load and load conditions and supply voltage disturbances.

In this paper, the method of solution has been decided based on the physical fact of the speed build-up of the induction machine. This physical insight is a must because the speed build-up of induction machine is equivalent to fluxlinkages build-up iterated with electromagnetic torque neglecting the stator flux transients in the full order model. This process governs the algorithm for solution of fluxlinkages and speed. The reduced order model demonstrates the improvement of the processing time considerably.

\section{ACKNOWLEDGMENT}

Sudhir Kumar sincerely acknowledges the valuable discussions made with Prof. (Dr.) A. B. Chattopadhyay, Birla Institute of Technology and Science, Pilani (Rajasthan) Dubai campus, and Professor Vivek Tiwari, National Institute of Technology, Jamshedpur (Jharkhand) India.

\section{REFERENCES}

[1] R. Genesio and M. Milanese, "A note on the derivation and use of reduced order models", IEEE Trans. Automat. Control, Vol. AC-21,No. 1, pp. 118-122, February 1976.

[2] M. S. Mahmoud and M. G. Singh, Large Scale Systems Modelling, Pergamon Press, International Series on Systems and Control 1st ed.,Vol. 3, 1981.

[3] M. Jamshidi, Large Scale Systems Modelling and Control Series, New York, Amsterdam, Oxford, North Holland, Vol. 9, 1983.

[4] S. K. Nagar and S. K. Singh, "An algorithmic approach for system decomposition and balanced realized model reduction", Journal of Franklin Inst., Vol. 341, pp. 615-630, 2004.

[5] V. Singh, D. Chandra and H. Kar, "Improved Routh Pade approximants:

A computer aided approach”, IEEE Trans. Automat. Control, Vol. 49, No.2, pp 292-296, February 2004. 
[6] S. Mukherjee, Satakshi and R.C.Mittal, "Model order reduction using response-matching technique", Journal of Franklin Inst., Vol. 342 , pp. 503-519, 2005.

[7] B. Salimbahrami, and B. Lohmann, "Order reduction of large scale second-order systems using Krylov subspace methods", Linear Algebra Appl., Vol. 415, pp. 385-405, 2006.

[8] S. Mukherjee and R.N. Mishra, "Reduced order modelling of linear multivariable systems using an error minimization technique", Journal of Franklin Inst., Vol. 325, No. 2, pp. 235-245, 1988.

[9] S. S. Lamba, R. Gorez and B. Bandyopadhyay, "New reduction technique by step error minimization for multivariable systems", Int. J.Systems Sci., Vol. 19, No. 6, pp. 999-1009, 1988.

[10] R. Prasad and J. Pal, "Use of continued fraction expansion for stable reduction of linear multivariable systems", Journal of Institution of Engineers, India, IE(I) Journal - EL, Vol. 72, pp. 43-47, June 1991.

[11] R. Prasad, A. K. Mittal and S. P. Sharma, "A mixed method for the reduction of multi-variable systems", Journal of Institution of Engineers,India, IE(I) Journal - EL, Vol. 85, pp. 177-181, March 2005.

[12] T.C. Chen, C.Y. Chang and K.W. Han, "Reduction of transfer functions by the stability equation method", Journal of Franklin Inst., Vol. 308, No. 4, pp. 389-404, 1979.

[13] T.C. Chen, C.Y. Chang and K.W. Han, "Model reduction using the stability equation method and the continued fraction method", Int. J. Control, Vol. 32, No. 1, pp. 81-94, 1980.

[14] C.P. Therapos, "Stability equation method to reduce the order of fast oscillating systems", Electronic Letters, Vol. 19, No.5, pp.183-184, March 1983.

[15] T.C. Chen, C.Y. Chang and K.W. Han, "Stable reduced order Pade approximants using stability equation method", Electronic Letters, Vol. 16, No. 9, pp. 345-346, 1980.

[16] J. Pal, "Improved Pade approximants using stability equation method",

Electronic Letters, Vol. 19, No.11, pp.426-427, May 1983.

[17] R. Parthasarathy and K.N. Jayasimha, "System reduction using stability equation method and modified Cauer continued fraction", Proceedings

IEEE, Vol. 70, No. 10, pp.1234-1236, October 1982

[18] G. G. Richard and O.T.Tan "Simplified model for induction machine transients under Balanced \& unbalanced condition", IEEE Trans. on industrial Application, Jan /Feb 1981.

[19] F.D.Radrigas and O.Waaynaxuk, "A method of representing isolated operation of Group of induction motor loads", IEEE Trans. on power systems, Vol. PWRS-2, No.3, pp. 568-575, August, 1987.

[20] Stag \& EI-Abiad, Computer method in power system analysis, 1968. International student edition.

[21] G.G Richard, "Reduced order model for an induction motor group during Bus-Transfer", IEEE Trans. on power system, Vol.1, No. 2 pp. 494-498, May 1989 .

[22] T.L. Savanna and P.C. Krause, "Accuracy of a Reduced order model of induction machine in dynamo-stability studies", IEEE Trans. on AC power app. \& system, Vol. PAS-98, No. 4, pp. 1192-1197, July/Aug 1979.

[23] S.Ertem andY.Baghzouz, "Simulation of induction machinery for power system studies", IEEE Trans. on Energy conversion, Vol- 4, No. 1, March 1989.

[24] D. Wasynvzuk, Y.Diao \&P.C. Krause, "Theory and comparison of reduced - order model of induction machines", IEEE Trans. power apparatus \& system, Vol. PAS 104, No.3, pp. 598-606, March 1985.

[25] D.G Shultz \& J.L. Melsa, State function and linear control system, McGraw Hill , 1957

[26] B. Adkins and R.Harley, The general Theory of Alternating Current Machine: Application to practical problems. London, Chapman and Hall, 1975

[27] P.C Krause and C.H Thomas, "Simulation of Electrical Machinery", IEEE Trans. Power Appratus and Systems, Vol..PAS-86, pp.1038-1053, Nov 1965.
[28] G.G. Richards and O.T Tan, "Decomposed, Reduced order Model for Double cage induction Machine", IEEE Trans. on Energy conversion, Vol. EC-1. No.3, pp. 87-93, Sep. 1986.

[29] N.A. Kh N.A. Khalil, O.T Tan, I.U Baran. "Reduced order model for double cage induction machines", IEEE Trans. power apparatus and System, Vol. PAS-101, No.9, pp. 3135.39, Sept. 1982.

[30] G. Parmar, S. Mukherjee and R. Prasad, "System reduction using factor division algorithm and eigen spectrum analysis", Applied Mathematical Modelling, Elsevier, Vol. 31, pp 2542-2552, 2007.

[31] G. Parmar, S. Mukherjee and R. Prasad, "Reduced order modelling of linear MIMO systems using Genetic Algorithm", Int. Journal of Simulation Modelling, Vol. 6, No. 3, pp. 173-184, 2007.

\section{AUTHORS PROFILE}

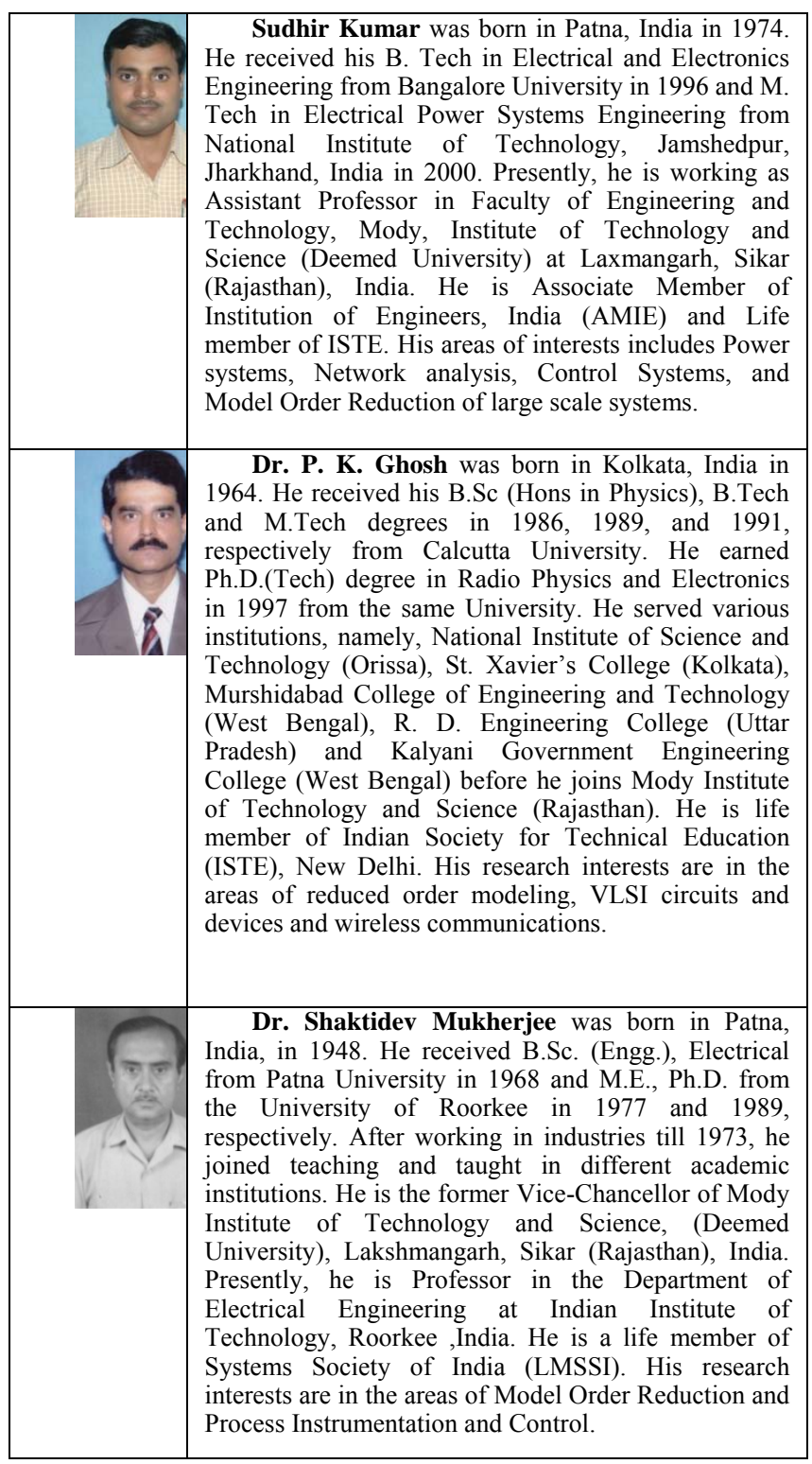

